\title{
DISTRIBUTION AND FIRST REPORTS OF BRANCHIOBDELLIDA (ANNELIDA: CLITELLATA) ON CRAYFISH IN THE PRAIRIE PROVINCES OF CANADA
}

\author{
Bronwyn W. Williams ${ }^{1,3}$, Stuart R. Gelder², and Heather Proctor ${ }^{1}$
}

\begin{abstract}
AвSTRACT.-Orconectes virilis (northern crayfish) were collected from 67 sites in Alberta, Saskatchewan, Manitoba, and far-western Ontario, Canada, and yielded 2 species of branchiobdellidans, Cambarincola vitreus and Cambarincola chirocephalus. This is the first report of branchiobdellidans in the Prairie Provinces. Cambarincola vitreus was distributed across the study area, but C. chirocephalus appeared to be restricted to southeastern Saskatchewan, southern Manitoba, and the site in western Ontario. Neither branchiobdellidan species was observed on crayfish in the Beaver River or the South Saskatchewan River and associated tributaries upstream (west) of Saskatoon, Saskatchewan, despite multiple sampling at these locations.
\end{abstract}

Key words: crayfish worm, Cambarincola spp., Cambarincola vitreus, Cambarincola chirocephalus, Orconectes virilis, host-symbiont distribution.

Branchiobdellidans, or crayfish worms, are obligate ectosymbionts primarily of astacoidean crayfishes (Brinkhurst and Gelder 2001). The distribution of branchiobdellidans in North America extends from Costa Rica north to the general area along the Canada-United States border (Gelder et al. 2002). Reports of branchiobdellidans in Canada are restricted to southern British Columbia (Gelder and Hall 1990), the St. Lawrence River drainage extending from Lake Erie and Lake Ontario to the river's mouth (Gelder et al. 2001) and New Brunswick (Gelder et al. 2009). Although branchiobdellidans have not been reported in the intermediate region (western Ontario and the Prairie Provinces) of Canada, potential hosts (Orconectes spp.) have been documented in these areas (Crocker and Barr 1968, Hamr 2002). The dearth of reports of branchiobdellidans from the Prairie Provinces likely results from inadequate targeted sampling (Gelder et al. 2002) or recent westward range expansion of crayfish. Unidentified branchiobdellidans were observed on a newly established population of Orconectes virilis (Hagen 1870), the northern crayfish, collected from the North Saskatchewan River in Edmonton, Alberta, in 2002 (H. Proctor personal observation). The historical range of $O$. virilis in Alberta extended along only the Beaver River drainage near the province's eastern border with Saskatchewan (Clifford 1991); however, recent collections demonstrate that $O$. virilis is now present in additional Albertan drainage systems in both the south and central parts of the province (Terry Clayton, Alberta Sustainable Resource Development, personal communication).

A recent study investigated and documented the occurrence of branchiobdellidans in New Brunswick for the first time (Gelder et al. 2009), establishing the eastern distributional limit of crayfish worms in North America. We initiated our study to establish the presence and distribution of branchiobdellidans in the Prairie Provinces with the additional intent of delineating the northern limit of branchiobdellidans in North America.

Northern crayfish were collected by "kicknetting" for up to 2 hours per site or in deployed Gee minnow traps (Wildlife Supply Company, Buffalo, NY) baited with salmon (Oncorhynchus sp.) and left for 12-24 hours. The minnow traps were modified to accommodate crayfish by increasing the entrance hole size to approximately $60 \mathrm{~mm}$. We sampled 67 sites across Alberta, Saskatchewan, Manitoba, and western Ontario near the border of Manitoba between August 2006 and November 2007 (Fig. 1, Appendix). We preserved each crayfish separately in a container of $95 \%$

\footnotetext{
${ }^{1}$ Department of Biological Sciences, University of Alberta, Edmonton, T6G 2E9, Alberta, Canada.

${ }^{2}$ Department of Science, University of Maine at Presque Isle, 181 Main Street, Presque Isle, ME 04769.

${ }^{3}$ E-mail: bwwillia@ualberta.ca
} 


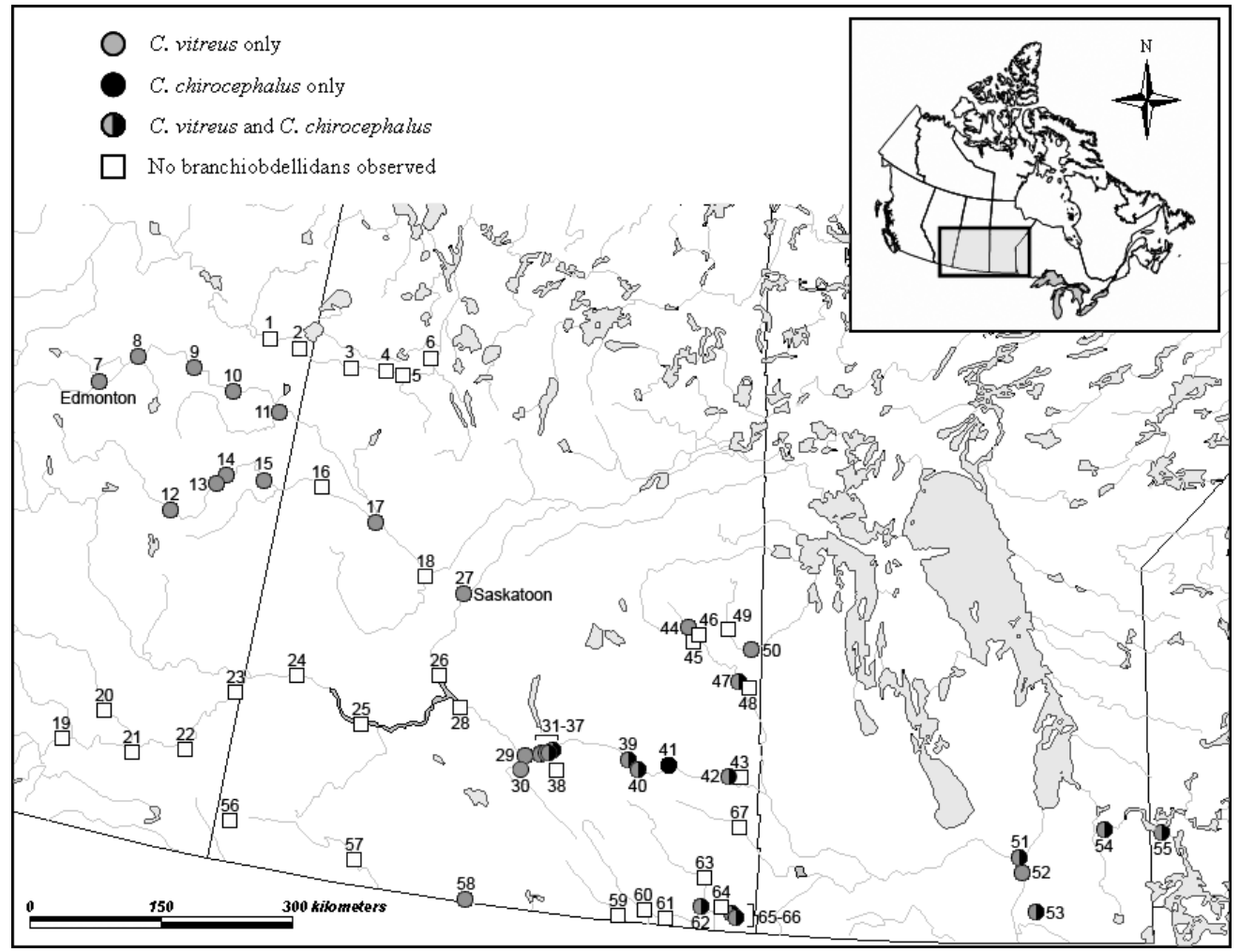

Fig. 1. Sampling locations of Orconectes virilis in Alberta, Saskatchewan, Manitoba, and Ontario showing detection or nondetection of 2 branchiobdellidan species, Cambarincola vitreus and C. chirocephalus. Numbers correspond to site numbers listed in the Appendix.

ethanol. In the laboratory, the external surface and branchial chambers of each crayfish, as well as debris at the bottom of the collection jar, were examined for branchiobdellidans under a dissecting microscope. We then transferred worms to labeled specimen jars containing fresh $95 \%$ ethanol. Stored branchiobdellidans were cleared in methyl salicylate, infiltrated with Canada balsam, and individually mounted on glass slides (Brinkhurst and Gelder 2001). We examined branchiobdellidans by using a compound microscope with both bright-field and differential interference contrast (DIC) illumination. Species identifications were made using information in Hoff$\operatorname{man}(1963)$.

Northern crayfish were collected from 66 sites across the Prairie Provinces and 1 site in far-western Ontario (Fig. 1; Appendix). We identified 2 species of branchiobdellidans from 35 sites: Cambarincola vitreus Ellis 1919 and Cambarincola chirocephalus Ellis 1919. Cam- barincola vitreus was distributed widely across the study area, whereas C. chirocephalus was observed only in southeastern Saskatchewan, southern Manitoba, and far-western Ontario. When C. vitreus and C. chirocephalus were found on crayfish from the same site, the species usually were cohabitant on a single crayfish. Branchiobdellidans were not detected at 32 sites, including multiple $(>5)$ sampling locations in the Beaver River and in the South Saskatchewan River and its associated tributaries upstream (west) of Saskatoon, Saskatchewan (Bow River, Oldman River). Additional rivers in Saskatchewan yielded no branchiobdellidans but were minimally sampled ( $\leq 2$ sites and/or $\leq 5$ crayfish).

Branchiobdellidan presence and distribution in the Prairie Provinces and in far-western Ontario, Canada, was unknown prior to this study. This study has established that 2 species of branchiobdellidans, C. vitreus and C. chirocephalus, inhabit $O$. virilis hosts in the region 
as a continuous extension of previously known ranges; C. vitreus and C. chirocephalus both occur widely throughout the Mississippi River drainage (Hoffman 1963, Gelder et al. 2002) and have been described from the northern Great Lakes and Great Plains states (Gelder et al. 2002).

The northern crayfish was the only crayfish collected during this study, despite records of additional Orconectes species in Manitoba and Ontario (Hamr 2002). Branchiobdellidans may exhibit a host preference when more than one host species is present (Brown and Creed 2004). Therefore, examinations of different crayfish species in the region may reveal additional branchiobdellidan species.

Nondetection of branchiobdellidans in many sampled waterways does not necessarily indicate true absence. The number of sampling locations and specimens collected were limited in certain areas. However, the lack of observations in intensively sampled river systems suggests that branchiobdellidan distribution may not be entirely coincident with host distribution. No branchiobdellidans were found on 47 crayfish examined from 6 sites along the Beaver River, the known northern limit of $O$. virilis distribution in Alberta and western Saskatchewan (Clifford 1991; I. Phillips, Saskatchewan Watershed Authority, personal communication). Although additional sampling is needed in the Beaver River and its mainstream, the Churchill River, absence of branchiobdellidans might result from an inability of the ectosymbionts to tolerate environmental conditions of northern latitudes (e.g., low temperatures and short ice-free season). In contrast, absence of branchiobdellidan observations in the South Saskatchewan River and associated tributaries upstream of Saskatoon is possibly related to the presence of 2 dams in central Saskatchewan. Cambarincola vitreus occurs on O. virilis downstream of the Gardiner Dam in the South Saskatchewan River, and C. chirocephalus was found on crayfish downstream of the Qu'Appelle River Dam in the Qu'Appelle River, but neither species was detected on any of the 200 crayfish examined from 9 sites upstream of the dams (Fig. 1).

Distribution patterns of branchiobdellidans can further our understanding of dispersal patterns of crayfish, as branchiobdellidan movement is contingent upon movement of the host. In addition, combined host-symbiont distribu- tion patterns may provide insight into ecological interactions between the associated organisms (Whiteman et al. 2004). The records we provide in our study will form the basis for future analyses of branchiobdellidan-crayfish relationships, including reasons for concomitant versus crayfish-only westward dispersal.

We thank Iain Phillips (Saskatchewan Watershed Authority, Saskatoon, SK); Drs. Lane Graham and Terry Galloway (University of Manitoba, Winnipeg, MB); Doug Watkinson (Fisheries and Oceans Canada, Winnipeg, MB); Kathryn Williams, Erica Kubanek, Lee Jeffers, Sascha Jeffers, and Philip DeWitt (University of Alberta, Edmonton, AB); and Dr. Jalene LaMontagne (University of Calgary, Calgary, AB) for assisting with specimen collections. Funding for field collection was provided to B.W. Williams and H. Proctor by the Alberta Conservation Association Grants in Biodiversity.

\section{Literature Cited}

Brinkhurst, R.O., And S.R. Gelder. 2001. Annelida: Oligochaeta including Branchiobdellidae. Pages 431463 in J.H. Thorp and A. Covich, editors, Ecology and classification of North American freshwater invertebrates. 2nd edition. Academic Press, New York.

Brown, B.L., AND R.P. CReED. 2004. Host preference by an aquatic ectosymbiotic annelid on 2 sympatric species of host crayfishes. Journal of the North American Benthological Society 23:90-100.

Clifford, H.F. 1991. Aquatic invertebrates of Alberta. University of Alberta Press, Edmonton, Alberta, Canada.

Crocker, D.W., AND D.W. Barr. 1968. Handbook of the crayfishes of Ontario. University of Toronto Press, Toronto, Ontario, Canada.

Gelder, S.R., H.C. Carter, and D.N. Lausier. 2001. Distribution of crayfish worms or branchiobdellidans (Annelida: Clitellata) in New England. Northeastern Naturalist 8:79-92.

Gelder, S.R., N.L. Gagnon, and K. Nelson. 2002. Taxonomic considerations and distribution of the Branchiobdellida (Annelida: Clitellata) on the North American continent. Northeastern Naturalist 9:451-468.

Gelder, S.R., ANd L.A. Hall. 1990. Description of Xironogiton victoriensis n.sp. from British Columbia, Canada, with remarks on other species and a Wagner analysis of Xironogiton (Clitellata: Branchiobdellida). Canadian Journal of Zoology 68:2352-2359.

Gelder, S.R., L. McCurry, And D.F. McAlpine. 2009. Distribution and first records of Branchiobdellida (Annelida: Clitellata) from crayfish in the Maritime provinces of Canada. Northeastern Naturalist 16: $45-52$.

Hamr, P. 2002. Orconectes. Pages 585-608 in D.M. Holdich, editor, Biology of freshwater crayfish. Blackwell Scientific Press, Oxford. 
Hoffman, R.L. 1963. A revision of the North American annelid worms of the genus Cambarincola (Oligochaeta: Branchiobdellidae). Proceedings of the United States National Museum 114:271-371.

Whiteman, N.K., D. Santiago-Alarcon, K.P. Johnson, AND P.G. PARKER. 2004. Differences in straggling rates between two genera of dove lice (Insecta: Phthi- raptera) reinforce population genetic and cophylogenetic patterns. International Journal for Parasitology 34:1113-1119.

Received 10 March 2008 Accepted 25 June 2008 


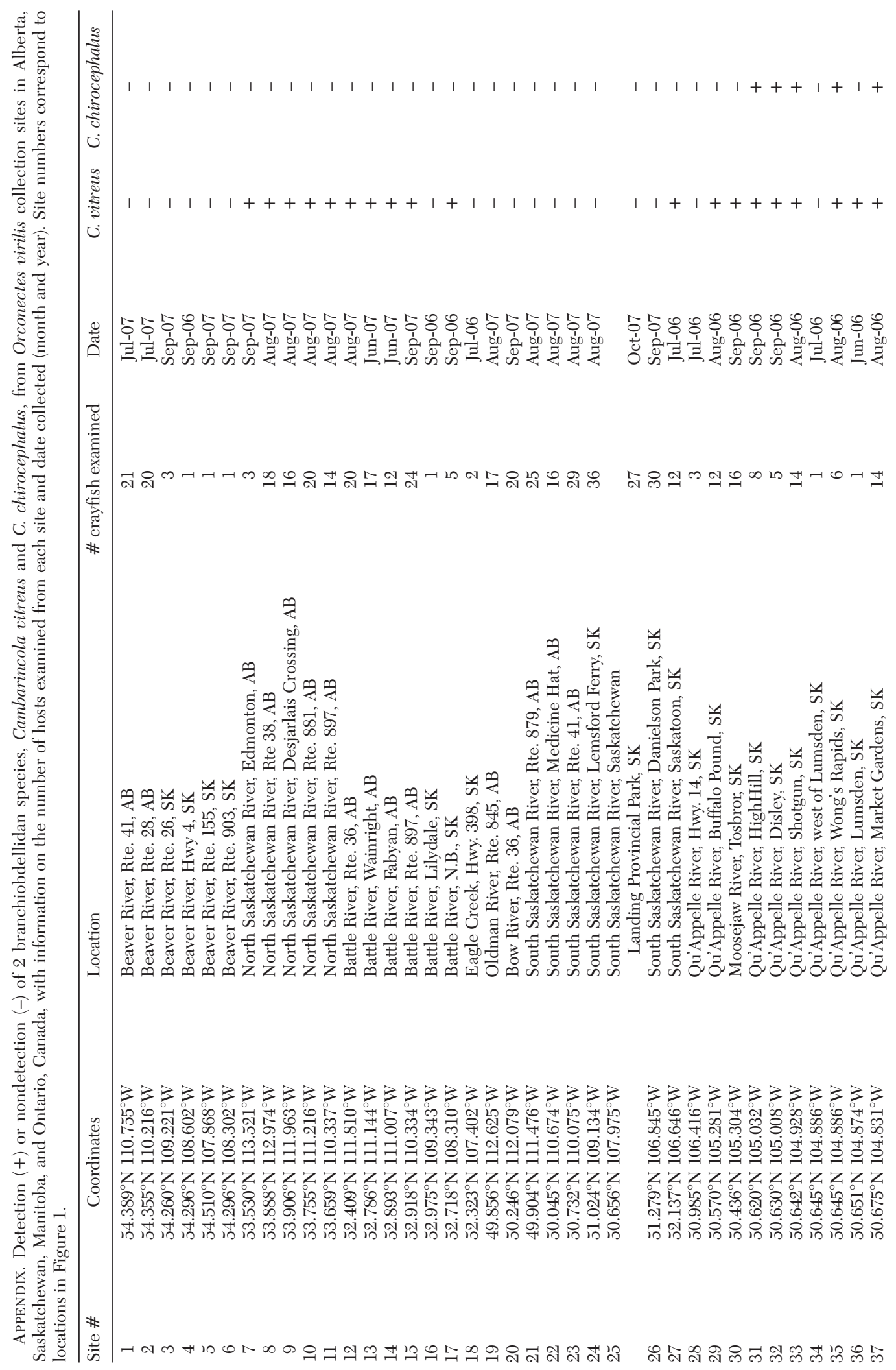




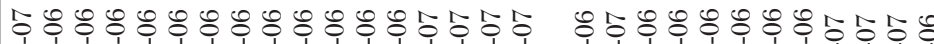

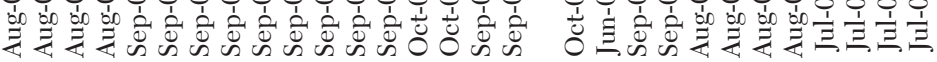

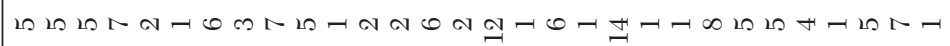

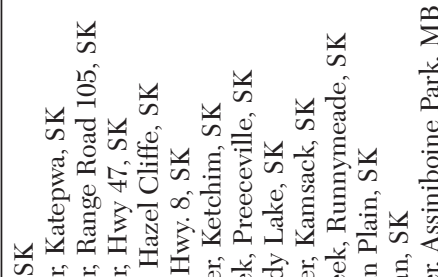

$\stackrel{n}{\sum}$ क से

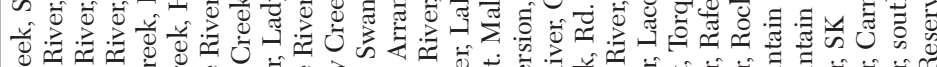

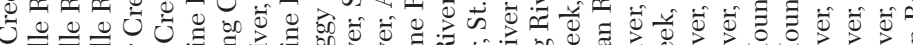

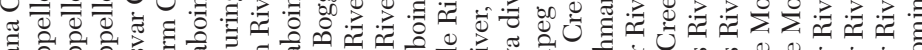

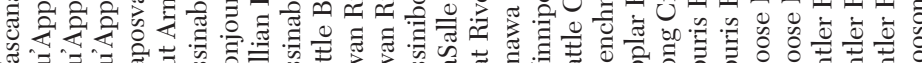

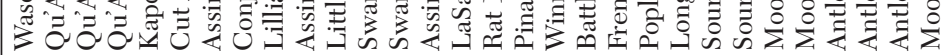

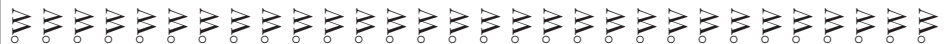

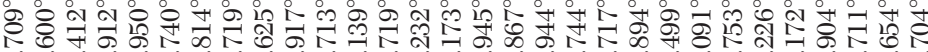

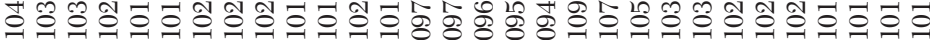

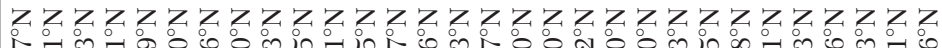

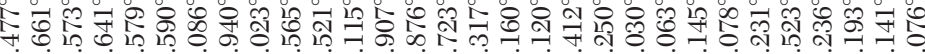

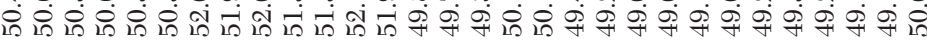

